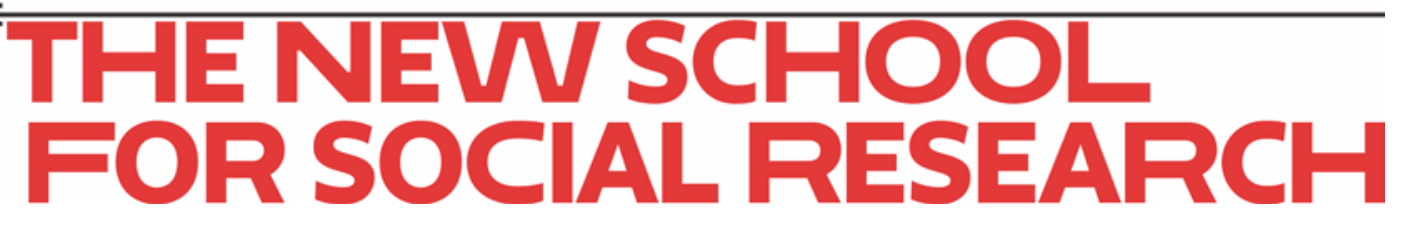

Gilberto Tadeu Lima, Mark Setterfield and Jaylson Jair da Silveira

\title{
The Great Deception: the 'science' of monetary policy and the Great Moderation revisited
}

October 2017

Working Paper 29/2017

Department of Economics

The New School for Social Research 


\title{
The Great Deception: the 'science' of monetary policy and the Great Moderation revisited"
}

\author{
Gilberto Tadeu Lima \\ Department of Economics, University of São Paulo, Brazil \\ giltadeu@usp.br \\ Mark Setterfield \\ Department of Economics, New School for Social Research, USA \\ mark.setterfield@newschool.edu \\ Jaylson Jair da Silveira \\ Department of Economics and International Relations \\ Federal University of Santa Catarina, Brazil \\ jaylson.silveira@ufsc.br
}

October 2017

\begin{abstract}
Conventional wisdom suggests that the Great Moderation was caused by either good policy, good luck (favourable shocks), more efficient private sector behaviour (such as better inventory management), or more effective financial innovations. We show that it may, instead, have originated from the complementarity of an erroneous reading of the economy by central bankers and evolutionarily time-varying heterogeneity in inflation expectations formation within the private sector. One general finding of our analysis is that seemingly inadequate stabilization policies may, in fact, work. We comment on the broader ramifications for stabilization policy of this finding.
\end{abstract}

Keywords: Great Moderation, monetary policy, inflation targeting, macroeconomic stability, heterogeneous inflation expectations, satisficing evolutionary dynamics.

J.E.L. Classification Codes: B52, E12, E31, E32, E52, E58, E71.

* Paper prepared for Bougrine, H and L.P. Rochon (eds) Money and Crises in PostKeynesian Economics: Essays in Honour of Marc Lavoie and Mario Seccareccia, Cheltenham, Edward Elgar (forthcoming). 


\section{Introduction}

Among their many timely interventions in the realm of monetary macroeconomics, the conference organized by Marc Lavoie and Mario Seccareccia at the University of Ottawa in the fall of 2003 has a particular bearing on this chapter. The conference (and the volume of essays that it produced - see Lavoie and Seccareccia, 2004) brought together various Post-Keynesian macroeconomists and monetary economists to reflect on the topic of modern central banking and, in particular, the New Consensus Macroeconomics that, although at that time still fairly recent, had already ascended to a position of prominence in academic and policy-making circles.

The conference also coincided with the emergence of an empirical literature identifying the onset of a "Great Moderation" - a widespread decline in the volatility of aggregate economic activity by a variety of measures (output, employment, inflation) since the early 1980s (see, for example, McConnell and Perez-Quiros, 2000; Blanchard and Simon, 2001; Stock and Watson, 2003). According to some, the timing of this Great Moderation and the rise to prominence of the New Consensus were no coincidence: "good policy” associated with the New Consensus - more specifically, good monetary policy codified in the Taylor rule and the single-minded pursuit of inflation targeting by independent central banks - were responsible for the onset of a more quiescent macroeconomic environment (Clarida, Cali, and Gertler, 2000; Galí \& Gambetti, 2009).

Other explanations for the Great Moderation quickly arose, including "good luck” (Stock and Watson, 2003), the beneficial effects of financial innovation (Dynan, Elmendorf, and Sichel, 2006), and better inventory control methods (Kahn, McConnell, and Perez-Quiros, 2002; Davis and Kahn, 2008). ${ }^{1}$ A more recent literature, meanwhile, has witnessed the emergence of "Great Moderation scepticism": never mind why the

\footnotetext{
${ }^{1}$ As noted by Bernanke (2004), none of these explanations are mutually exclusive.
} 
Great Moderation happened, the question is whether, in fact, it happened at all. Keating and Valcarcel (2017), for example, suggest that the reduction in macroeconomic volatility during the Great Moderation pales by comparison with the reduction in volatility achieved immediately after WWII - and that while the latter is statistically significant, the former is not. Elsewhere the Great Moderation is presented as a statistical mirage. Crowley and Hughes Hallett (2014) argue that the Great Moderation was an illusion caused by a change in the statistical composition of aggregate volatility. Assa (2017), meanwhile, posits a Great Moderation illusion caused by the "financialization” of national income accounting - a series of changes in the definition of value added that covered up "volatility as usual" during the post-1980 period.

The approach taken in this chapter is different again. We return to the "Great Moderation as a product of good monetary policy” hypothesis, but suggest instead a “Great Deception” - that any Great Moderation was an innocent fraud, resulting not from successful stabilization policy that validated the New Consensus and its overwhelming policy emphasis on inflation targeting, but from unacknowledged aspects of private sector behaviour (especially as regards inflation expectations formation) that complemented an otherwise erroneous reading of the economy by monetary authorities. One upshot of our analysis is that seemingly inadequate stabilization policies may, in fact, work, when heterogeneity in the strategies used to form inflation expectations within the private sector are endogenously time-varying. We show that this analytical finding is far from trivial, commenting on its broader implications for stabilization policy, especially with respect to central bank management of heterogeneous inflation expectations formation.

The remainder of the chapter is organized as follows. Section 2 sets out our main analytical results, including the result that stabilization policy may work despite seemingly violating the Tinbergen (1952) principle, provided it is (unintentionally) 
complemented by the "right” private sector behaviour in terms of inflation expectations formation. Section 3 discusses the broader consequences of this result for the conduct of stabilization policy. Finally, section 4 concludes.

\section{Analytical Results}

\section{i) A benchmark model}

Drawing on Lima and Setterfield (2008), we begin with the following benchmark macroeconomic model:

$$
\begin{aligned}
& y=y_{0}-\delta r, \\
& p=\beta+\varphi p^{e}+\alpha y, \\
& \dot{r}=\lambda\left(y-y^{T}\right)+\gamma\left(p-p^{T}\right), \\
& p^{e}=p^{T},
\end{aligned}
$$

where $y$ denotes the level of real output, $y_{0}$ represents non-interest sensitive components of aggregate spending, $p$ and $p^{e}$ are the actual and expected rates of inflation, respectively, $r$ is the real interest rate, $y^{T}$ denotes the policy authorities' target level of real output, and $p^{T}$ is their target rate of inflation. Meanwhile, $\beta$ denotes an exogenous component in inflation dynamics and the other Greek letters represent strictly positive parameters. As usual, a dot over a variable denotes its rate of change (i.e., $\dot{x}=d x / d t$ ). Equation (1) is simply an aggregate demand schedule, equation (2) is an expectations-augmented Phillips curve, equation (3) is a monetary policy rule and equation (4) describes inflation expectations formation. Regarding (2), it is reasonable to further assume that $\varphi<1$, which is consistent with the notion that workers lack the bargaining power to fully index expected inflation into nominal wage growth. 
The rationale for this benchmark model is as follows. The "true model” has a PostKeynesian structure (codified in the existence of a long run relationship between $p$ and $y$ evident in the Phillips curve in equation (2) and the conventional method of expectations formation in equation (4)) of the sort associated with the work of Lavoie and Seccareccia. $^{2}$ The policy maker is neoclassical, however. It uses only one instrument $(r)$ to pursue two targets ( $y^{T}$ and $p^{T}$ ) in the Taylor-rule-like monetary policy rule in equation (3). This is based on the mistaken belief that $y$ is inherently self-regulating about a "natural" level of real output determined exclusively on the supply-side of the economy, that policy makers can successfully estimate and incorporate (in the form of $y^{T}$ ) into their policy rule. The model therefore presents a Tinbergen (1952) problem in the making - and this is exactly what materializes. ${ }^{3}$ To see this, note that by taking into account the description of inflation expectations in (4), we can differentiate (2) with respect to time and arrive at:

$$
\dot{p}=\alpha \dot{y}
$$

Differentiating (1) with respect to time and using (3), we obtain:

$$
\dot{y}=-\delta\left[\lambda\left(y-y^{T}\right)+\gamma\left(p-p^{T}\right)\right],
$$

and substitution of (6) into (5) yields:

$$
\dot{p}=-\alpha \delta\left[\lambda\left(y-y^{T}\right)+\gamma\left(p-p^{T}\right)\right] .
$$

Finally, if we again differentiate (5-a) with respect to time and use (5), we arrive at:

\footnotetext{
${ }^{2}$ In fact, sound Post Keynesian behavioral foundations for this benchmark model - and in particular, (1) and (2) - are provided in Lima and Setterfield (2014) by drawing (inter alia) on the work of Lavoie and Seccareccia. It is shown there that (1) approximates the relationship between real output and the real interest rate in a standard Kaleckian macroeconomic model in which firms' net profits (and hence their investment decisions) are sensitive to their debt service. Meanwhile, (2) approximates the relationship between inflation and real output arising from conflicting-claims wage and price dynamics when firms follow target-return pricing that is sensitive to their debt service.

${ }^{3}$ A "Tinbergen problem" refers here to the use of too few (linearly independent) policy instruments in the pursuit of too many (linearly independent) policy targets.
} 


$$
\ddot{p}+\delta(\lambda+\alpha \gamma) \dot{p}=0
$$

The general solution of the homogenous linear second-order differential equation in (7) can be stated as:

$$
p(t)=-\frac{c_{1}}{\delta(\lambda+\alpha \gamma)} e^{-\delta(\lambda+\alpha \gamma) t}+c_{2},
$$

where $C_{1}$ and $C_{2}$ are constants of integration. From (8), we can obtain the change rate of inflation at period $t$ as:

$$
\dot{p}(t)=c_{1} e^{-\delta(\lambda+\alpha \gamma) t} .
$$

For given initial conditions $(y(0), p(0))$, we can now use (5-a) to determine the initial magnitude of the change in inflation:

$$
\dot{p}(0)=-\alpha \delta\left\{\lambda\left[y(0)-y^{T}\right]+\gamma\left[p(0)-p^{T}\right]\right\},
$$

and based on (9) and (10), we are able to determine the first constant of integration:

$$
c_{1}=-\alpha \delta\left\{\lambda\left[y(0)-y^{T}\right]+\gamma\left[p(0)-p^{T}\right]\right\} .
$$

Combining (11) with (8), we can then find the remaining constant of integration:

$$
c_{2}=p(0)-\frac{\alpha\left\{\lambda\left[y(0)-y^{T}\right]+\gamma\left[p(0)-p^{T}\right]\right\}}{\lambda+\alpha \gamma} .
$$

Finally, substituting (11) and (12) into the general solution (8), we obtain the definite solution of (7):

$$
p(t)-p^{T}=\frac{\lambda\left\{\left[p(0)-p^{T}\right]-\alpha\left[y(0)-y^{T}\right]\right\}}{\lambda+\alpha \gamma}+\frac{\alpha\left\{\gamma\left[p(0)-p^{T}\right]+\lambda\left[y(0)-y^{T}\right]\right\}}{\lambda+\alpha \gamma} e^{-\delta(\lambda+\alpha \gamma) t} .
$$

If we now evaluate the limit of (13) as $t \rightarrow \infty$, we obtain:

$$
p^{*}-p^{T} \equiv \lim _{t \rightarrow \infty} p(t)-p^{T}=\frac{\lambda\left\{\left[p(0)-p^{T}\right]-\alpha\left[y(0)-y^{T}\right]\right\}}{\lambda+\alpha \gamma} .
$$


Hence, for a given set of initial conditions $(y(0), p(0))$, the economy will converge to $p^{*}=p^{T}$ if for all $\lambda+\alpha \gamma \neq 0$ we have:

$$
\lambda\left\{\left[p(0)-p^{T}\right]-\alpha\left[y(0)-y^{T}\right]\right\}=0 .
$$

Assuming that the initial conditions of the economy $(y(0), p(0))$ are generally such that $\left[p(0)-p^{T}\right]-\alpha\left[y(0)-y^{T}\right] \neq 0$, the condition in (15) will be satisfied if and only if $\lambda=0$. In short, the economy will converge to an equilibrium configuration with $p^{*}=p^{T}$ only if the monetary authority uses monetary policy exclusively to target inflation $(\lambda=0) .^{4}$

What will be the equilibrium level of real output if $p^{*} \rightarrow p^{T}$ ? Based on (2) and (4), we can identify the long-run equilibrium level of real output as:

$$
y^{*} \equiv \lim _{t \rightarrow \infty} y(t)=\lim _{t \rightarrow \infty} \frac{p(t)-\beta+\varphi p^{T}}{\alpha}=\frac{p^{*}-\beta+\varphi p^{T}}{\alpha} .
$$

Considering (14) and (15), it follows that if $p^{*} \rightarrow p^{T}$ in the limit:

$$
y^{*}=\frac{(1-\varphi) p^{T}-\beta}{\alpha}
$$

There is, then, no "full compatibility" of inflation targeting with the underlying structure of the economy. In other words, the policy maker's inflation target is realized in equilibrium (so that inflation targeting is partially compatible with the underlying structure of the economy), but their output target is not. Instead, as indicated in (17), the

\footnotetext{
${ }^{4}$ Suppose, alternatively, that we are interested instead in asking whether the economy will converge to an equilibrium configuration characterized by $y^{*}=y^{T}$. If we now again differentiate (6) with respect to time and use (5), we arrive at $\ddot{y}+\delta(\lambda+\alpha \gamma) \dot{y}=0$. Following the same algebraic steps leading from (8) to (15), we find that the economy will converge to an equilibrium solution with $y^{*}=y^{T}$ only if the monetary authority now uses monetary policy exclusively to target output $(\gamma=0)$.
} 
policy maker "discovers” the true structure of the Phillips curve relationship inherent in the Post-Keynesian structure of the economy - involving a direct long-run relationship between output and inflation - in the course of adjusting their policy intervention (by setting $\lambda=0$ ) to ensure the achievement of their priority (inflation) target, and by then accepting the accompanying equilibrium level of output (in (17)) as an endogenous residual. Although the monetary authority holds the mistaken belief that $y$ is inherently self-regulating about a "natural" level determined solely by supply factors, the achievement of the inflation target is in fact accompanied by an equilibrium output that is an endogenous demand-led residual (although the structural features represented by $\alpha$ , $\beta$ and $\varphi$, with each of which the equilibrium output in (17) varies negatively, reflect supply-side behaviour through the expectations-augmented Phillips curve in (2)). Moreover, this equilibrium output is directly related to the inflation target chosen by the monetary authority: had a lower inflation target been chosen (without compromising the confidence held by the private sector in the conventional method of expectations formation in (4)), achievement of the inflation target would then be accompanied by a lower equilibrium output.

The basic structure of this baseline model may be broadly appealing to many PostKeynesians. It posits that the "true model" is fundamentally Post-Keynesian, but allows for the fact that the central bank adheres to a neoclassical subjective model of the economy and sets up its policy intervention accordingly, treating its target level of output as a given and claiming discretion only over the value of the inflation target. The results of the model, however, pose various problems. The first is the seeming indifference of the policy maker to $y$ manifest in the permanent (equilibrium) output gap $y^{*} \neq y^{T}$, which outcome is unavoidable unless, by chance, the monetary authority begins by setting $y^{T}=\left[(1-\varphi) p^{T}-\beta\right] / \alpha$, as indicated in (17). Both indifference to a permanent output 
gap (which, according to the subjective model of the policy maker, would unleash the cumulative inflationary or disinflationary forces associated with the accelerationist hypothesis $\left.\dot{p}=f\left(y-y^{T}\right), f^{\prime}>0\right)$ and the condition necessary to avoid this outcome seem fanciful. It may be that belief in a strong enough hysteresis effect (of the sort conjectured, in a different context, by Lavoie $(1995,1996))$ justifies policy maker’s indifference to the equilibrium value of $y$. But even then, we are left with a second problem. The fact is that monetary authorities clearly do pay attention to $y$ even as they focus on inflation targeting, so the monetary policy rule in the baseline model (in which $\lambda \neq 0$ ) appears to be misspecified.

Does this mean that fault perhaps lies with the (Post-Keynesian) specification of the "true model" in the analysis above? Do central banks have the "true model” specified correctly (as neoclassical) after all? Not necessarily.

ii) Other policy interventions as a source of successful stabilization

Consider now the most general model that appears in Lima and Setterfield (2008), in which both a Taylor-rule-like central bank reaction function and an incomes policy reaction function exist and respond to both the output and inflation gap:

$$
\begin{aligned}
& y=y_{0}-\delta r, \\
& p=\beta+\varphi p^{e}+\alpha y+\theta Z, \\
& \dot{r}=\lambda\left(y-y^{T}\right)+\gamma\left(p-p^{T}\right), \\
& p^{e}=p^{T}, \\
& \dot{Z}=-\psi\left(y-y^{T}\right)-\mu\left(p-p^{T}\right),
\end{aligned}
$$

where $Z$ captures the willingness and ability of workers to bid up the rate of growth of nominal wages independently of the level of economic activity as measured by the level 
of output (the further Greek letters appearing in (2-a) and (18) again represent strictly positive parameters). As in Lima and Setterfield (2008), the policy instrument for enacting changes in $Z$ in (18) is deemed to be some form of incomes policy. In this context, incomes policies are defined as formal and/or informal institutions and arrangements that frame and mediate aggregate wage and price setting behaviour in such a manner as to attenuate conflict over income shares and better reconcile conflicting income claims. In fact, incomes policies so-defined can be either cooperative or coercive (or a combination of both), which depends on whether the objective is to reconcile competing income claims in a mutually satisfactory way, or simply and inevitably compel one bargaining party (either firms or workers) to accept the distributional claims of the other. Therefore, the precise policy instrument enacted in order to reduce $Z$ might involve, for instance, centralizing wage bargaining or changing labour law to reduce the job-security of workers. It is to be expected that any incomes policy will ultimately reflect the distribution of power in society. As a result, cooperative incomes policies can arise when labour has sufficient bargaining power, but there can also be coercive incomes policies that contain inflation, but are essentially an expression of capital's bargaining power vis a vis labour and its concomitant ability to actually dictate the distribution of income. $^{5}$

By combining equations (1), (2-a), (3), (4) and (18), Lima and Setterfield (2008, pp. 454) obtain the following dynamic system:

$$
\begin{aligned}
& \dot{y}=-\delta \lambda\left(y-y^{T}\right)-\delta \gamma\left(p-p^{T}\right), \\
& \dot{p}=-(\alpha \delta \lambda+\theta \psi)\left(y-y^{T}\right)-(\alpha \delta \gamma+\mu \theta)\left(p-p^{T}\right) .
\end{aligned}
$$

\footnotetext{
${ }^{5}$ Setterfield (2007) shows that an incomes policy of this sort has operated in the US economy over most of the Great Moderation period.
} 
This dynamic system has one, and only one, equilibrium configuration which is given by $\left(y^{T}, p^{T}\right)$. The Jacobian matrix $J$ of partial derivatives of the dynamic system composed of (19) and (20) evaluated around the unique equilibrium is given by:

$$
J\left(y^{T}, p^{T}\right)=\left[\begin{array}{c|c}
-\delta \lambda & -\delta \gamma \\
\hline-(\alpha \delta \lambda+\theta \psi) & -(\alpha \delta \gamma+\mu \theta)
\end{array}\right] .
$$

As we have $\operatorname{Tr}\left(J\left(y^{T}, p^{T}\right)\right)=-\delta(\lambda+\alpha \gamma)-\mu \theta<0$, it follows that the sign of $\operatorname{Det}\left(J\left(y^{T}, p^{T}\right)\right)=\delta \theta(\lambda \mu-\gamma \psi)$ determines the local stability of the equilibrium given by $\left(y^{T}, p^{T}\right)$. The system will be asymptotically stable as long as:

$$
\frac{\mu}{\psi}>\frac{\gamma}{\lambda}
$$

This means that there will be full compatibility of inflation targeting with the underlying structure of the economy (that is, both the inflation and output targets will be realized in equilibrium) as long as the elected authority responsible for enacting the incomes policy assigns a relative weight to the inflation gap with respect to output gap $(\mu / \psi)$ that is greater than the respective relative weight assigned by the monetary authority $(\gamma / \lambda)$. Under these conditions, the incomes policy works as a stabilizing force that offsets the destabilizing effect generated by an independent monetary authority focused mostly on inflation targeting - ironically, as a result of the incomes policy itself being even more zealously devoted to pursuit of the inflation target.

In this extended set up, we now have a Taylor-type interest rate rule, so that the specification of the monetary authority's behaviour seems realistic. At the same time, the underlying structure of the economy is Post-Keynesian, despite the neoclassical mores of the monetary authority. Finally, the tensions between the "true model" of the economy and the subjective model of the monetary authority that were manifest in the benchmark 
case are here eased by the effects of a second policy mechanism, which ensures that stabilization policy works (both policy targets are realized in equilibrium). As a result, inflation targeting by the central bank (which erroneously treats aggregate real output in neoclassical fashion, as inherently self-regulating) is rendered fully compatible with the (Post-Keynesian) structure of the economy.

The problem that remains is, however, obvious: is this "offsetting second policy mechanism” really what we see in reality? Surely the Post-Keynesian complaint of “monetary policy dominance" - the notion that macroeconomic policy has devolved to the point where it consists of little more than monetary policy conducted by an independent, inflation targeting central bank - would suggest not.

iii) An alternative: evolutionarily time-varying heterogeneity in inflation expectations as the source of a Great Deception

Following Lima, Setterfield and Silveira (2014), we now substitute heterogeneous inflation expectations formation for the incomes policy reaction function in (18) and the description of conventional expectations formation in (4), which implicitly assigns full credibility to the policy authorities' commitment to achieve $p^{T}$ (so that all decision makers use this target as the basis for their inflation expectations). Under these conditions, the same stability outcomes revealed in the previous sub-section can be shown to emerge.

Keeping the sub-model (1)-(3) drawn from Lima and Setterfield (2008) and adding a new expectational equation and the noisy satisficing evolutionary dynamics drawn from Lima, Setterfield and Silveira (2014), the basic macroeconomic model on which our analysis now rests can be stated as follows:

$$
\begin{aligned}
& y=y_{0}-\delta r, \\
& p=\beta+\varphi p^{e}+\alpha y,
\end{aligned}
$$




$$
\begin{aligned}
& \dot{r}=\lambda\left(y-y^{T}\right)+\gamma\left(p-p^{T}\right), \\
& \dot{p}^{e}=-(1-k)\left(p-p^{T}\right), \\
& \dot{k}=(1-\varepsilon)\left\{(1-k) F\left(\left(p-p^{T}\right)^{2}\right)-k\left[1-F\left(\left(p-p^{T}\right)^{2}\right)\right]\right\}+\varepsilon\left(\frac{1}{2}-k\right) .
\end{aligned}
$$

As in the benchmark model, the neoclassically-minded central bank is the only active policy authority, and uses one instrument to pursue two targets in a Taylor-rule-like interest rate operating procedure (equation (3)), assuming that aggregate real output will adjust automatically towards a supply-determined natural level that it has successfully estimated (as $y^{T}$ ).

In accordance with a core presupposition associated with the work of Lavoie and Seccareccia, in an environment of fundamental uncertainty surrounding the future, no economic agent (including the monetary authority) is assumed to be capable of forming rational expectations. In fact, the specification in (23) is based on the considerable empirical evidence from both survey data and laboratory experiments suggesting that inflation expectations are persistently heterogeneous and formed through boundedly rational mechanisms (see, e.g., Hommes, 2013). As validated by such extensive empirical evidence, agents are assumed to form expectations using one of two heuristics, but can (and eventually do) switch between these heuristics over time.

In (23), $k \in[0,1] \subset \mathbb{R}$ denotes the proportion of incredulous agents who form expectations in accordance with current inflation, and $1-k$ denotes the proportion of credulous agents whose expectations are anchored to the official inflation target. The term $(1-k) \in[0,1] \subset \mathbb{R}$ can be thought of as measuring the credibility of the policy authorities' commitment to achieve $p^{T}$ (as in Lima and Setterfield, 2008). More importantly, it can also be thought of as varying endogenously over time as a result of satisficing evolutionary dynamics (with and without noise) in the spirit of the contributions of 
Herbert Simon. According to Simon $(1955,1956)$, reality is complicated relative to the information collecting and processing and decision making capacities of the individual. Denied the ability to optimize based on knowledge of the "true model" describing reality, decision makers (including monetary authorities) must instead "muddle through" using boundedly rational heuristics and satisficing criteria as the bases for their expectations and attendant decision making. In this context, as elaborated by Simon (1955, 1956), satisficing is nonetheless a theory of choice centred on the mental process through which available alternatives are reasonably examined and evaluated. Yet choice is seen as a process of meeting an acceptability threshold rather than selecting the best of all alternatives. Decision makers are constrained to engage in satisficing rather than optimizing behaviour.

As in Lima, Setterfield and Silveira (2014), (23) is formally derived as follows. The rate of change of expected inflation is a weighted average of the rate of change of expected inflation by incredulous agents $\left(\dot{p}_{i}^{e}\right)$ and the rate of change of expected inflation by credulous $\left(\dot{p}_{c}^{e}\right)$ agents: $\dot{p}^{e}=k \dot{p}_{i}^{e}+(1-k) \dot{p}_{c}^{e}$. As credulous agents expect the convergence of current inflation to the policy target, $p^{T}$, while incredulous agents expect inflation to remain unchanged, it follows that $\dot{p}_{c}^{e}=p^{T}-p$ and $\dot{p}_{i}^{e}=0$. Hence, substituting these expressions for $\dot{p}_{c}^{e}$ and $\dot{p}_{i}^{e}$ into the expression for $\dot{p}^{e}$ stated above yields (23).

Meanwhile, (24) represents the satisficing evolutionary dynamics that drive the degree of credibility in the commitment of the policy authorities to achieve $p^{T}$ (i.e., the proportion of credulous agents, 1-k). Based on the full derivation in Lima, Setterfield and Silveira (2014), the substance of such evolutionary dynamics can be intuitively explained as follows. An agent $j$ takes the gap between current inflation and the inflation 
target, $p-p^{T}$, and compares it (ignoring its sign) with the gap they consider acceptable, $p^{j}-p^{T}$. If the observed gap is equal to or smaller than (in module) the acceptable gap, agent $j$ does not consider switching their strategy for forming inflation expectations. Otherwise agent $j$ becomes a strategy reviser. ${ }^{6}$ As the gap that an agent finds acceptable reflects, inter alia, idiosyncratic features, we assume that acceptable gaps are randomly and independently determined across agents and over time. Specifically, we assume that the square of the tolerable gap is a random variable with a cumulative distribution function $F$. We can then compute the probabilities of randomly choosing an agent $j$ who considers a current deviation $p-p^{T}$ as either unacceptable or acceptable, and thereby both the measure of credulous agents who become incredulous and the measure of incredulous agents who become credulous.

We also consider the possibility that these satisficing evolutionary dynamics operate in the presence of a noise term, analogous to mutation in natural environments. In a biological setting, mutation is usually interpreted literally as consisting of random changes in genetic codes. In economic settings, mutation can be interpreted as referring to a situation in which a decision maker refrains from comparing payoffs and switches strategy randomly. In this context, the noise component captures the effect of, for instance, exogenous institutional factors, such as changes of administration in the monetary authority, or other changes in the policy-making framework (which nonetheless do not involve an abandonment of the inflation targeting regime). By letting $\varepsilon \in(0,1) \subset \mathbb{R}$ be the measure of mutant agents (who choose an inflation predictor

\footnotetext{
${ }^{6}$ The fact that policy authorities usually target a range rather than a single rate of inflation, thus implicitly expecting (and subsequently tolerating) some variation of current inflation within this range, provides further reasonable behavioural motivation for our modelling of agents as accepting some tolerable deviation of inflation from their forecasts.
} 
independently of the respective payoffs), after further algebraic manipulation we finally arrive at the noisy satisficing evolutionary dynamics in (24).

By combining (1)-(3) and (23)-(24), we arrive at the following dynamic system:

$$
\begin{aligned}
& \dot{y}=-\delta \lambda\left(y-y^{T}\right)-\delta \gamma\left(p-p^{T}\right), \\
& \dot{p}=-\alpha \delta \lambda\left(y-y^{T}\right)-[\varphi(1-k)+\alpha \delta \gamma]\left(p-p^{T}\right), \\
& \dot{k}=(1-\varepsilon)\left\{(1-k) F\left(\left(p-p^{T}\right)^{2}\right)-k\left[1-F\left(\left(p-p^{T}\right)^{2}\right)\right]\right\}+\varepsilon\left(\frac{1}{2}-k\right) .
\end{aligned}
$$

This dynamic system has a unique equilibrium which is given by $\left(y^{T}, p^{T}, \varepsilon / 2\right)$. Its Jacobian matrix evaluated around this equilibrium is given by:

$$
J\left(y^{T}, p^{T}, \varepsilon / 2\right)=\left[\begin{array}{c|c|c}
-\delta \lambda & -\delta \gamma & 0 \\
\hline-\alpha \delta \lambda & -(\varphi(1-\varepsilon / 2)+\alpha \delta \gamma) & 0 \\
\hline 0 & 0 & -1
\end{array}\right]
$$

Let $\xi$ be an eigenvalue of the Jacobian matrix (26). We can then write the characteristic equation of the system linearized around its unique equilibrium as:

$$
|J-\xi I|=\xi^{3}+a_{2} \xi^{2}+a_{1} \xi+a_{0}=0
$$

where:

$$
\begin{aligned}
a_{0} & =-\operatorname{Det}(J)=\delta \lambda \varphi\left(1-\frac{\varepsilon}{2}\right)>0 \\
a_{1} & =\left|\begin{array}{cc}
-(\varphi(1-\varepsilon / 2)+\alpha \delta \gamma) & 0 \\
0 & -1
\end{array}\right|+\left|\begin{array}{cc}
-\delta \lambda & 0 \\
0 & -1
\end{array}\right|+\left|\begin{array}{cc}
-\delta \lambda & -\delta \gamma \\
-\alpha \delta \lambda & -(\varphi(1-\varepsilon / 2)+\alpha \delta \gamma)
\end{array}\right| \\
& =\varphi\left(1-\frac{\varepsilon}{2}\right)+\alpha \delta \gamma+\delta \lambda+\delta \lambda \varphi\left(1-\frac{\varepsilon}{2}\right)>0
\end{aligned}
$$

$$
a_{2}=-\operatorname{Tr}(J)=\delta \lambda+\varphi\left(1-\frac{\varepsilon}{2}\right)+\alpha \delta \gamma+1>0
$$

We can further establish that: 


$$
\begin{aligned}
& a_{1} a_{2}-a_{0}=\left[\varphi\left(1-\frac{\varepsilon}{2}\right)+\alpha \delta \gamma+\delta \lambda+\delta \lambda \varphi\left(1-\frac{\varepsilon}{2}\right)\right]\left[\delta \lambda+\varphi\left(1-\frac{\varepsilon}{2}\right)+\alpha \delta \gamma+1\right]-\delta \lambda \varphi\left(1-\frac{\varepsilon}{2}\right) \\
& =\left[\varphi\left(1-\frac{\varepsilon}{2}\right)+\alpha \delta \gamma+\delta \lambda+\delta \lambda \varphi\left(1-\frac{\varepsilon}{2}\right)\right]\left[\delta \lambda+\varphi\left(1-\frac{\varepsilon}{2}\right)+\alpha \delta \gamma\right]+\varphi\left(1-\frac{\varepsilon}{2}\right)+\alpha \delta \gamma+\delta \lambda>0 .
\end{aligned}
$$

Based on (28)-(31), we know that the Routh-Hurwitz criterion for local stability of the equilibrium given by $\left(y^{T}, p^{T}, \varepsilon / 2\right)$ is satisfied. This means that there is once again full compatibility of inflation targeting with the underlying structure of the economy for any constellation of model parameters.

In this model, the satisficing evolutionary dynamic governing heterogeneous private sector inflation expectations acts as a surrogate policy instrument, so that two official targets can be successfully pursued using one (explicit) instrument, seemingly in violation of the Tinbergen (1952) principle. One result, as we have already seen, is that equilibrium outcomes are now consistent with the target values set by the central bank. In fact, both the inflation and output targets will be achieved even if monetary policy is the only explicit policy instrument in use. The intuition is that the Tinbergen (1952) principle (that there needs to be as many linearly independent policy instruments as linearly independent policy goals) is still satisfied, as there are still two linearly independent adjusting variables (viz. the interest rate, $r$, and now the degree of credibility of the policy authorities, measured by $1-k$ ) ensuring the achievement of two linearly independent targets (inflation and output). In fact, full credulity (or full credibility of the monetary authority) can be interpreted as another implicit policy target, the achievement of which is a by-product of achieving the inflation target (at least when $\varepsilon=0$ ). Interestingly, therefore, private agents actively contribute to successful monetary policy by using heterogeneous strategies to form inflation expectations, and by switching such 
strategies in a boundedly rational, satisficing manner. In other words, although the "name of the game” in monetary policy is often said to be the management of expectations, it appears that endogenously time-varying heterogeneity in the strategies used by the private sector to form inflation expectations in accordance with satisficing evolutionary dynamics may actually (albeit unintentionally) be a blessing rather than a curse. Moreover, our analytical results show that inflation targeting may succeed in anchoring inflation expectations even if heterogeneity in the strategies used to form inflation expectations emerges as an equilibrium outcome of satisficing evolutionary dynamics.

A second result, which follows from the first, is that the central bank is now entitled to feel that the (neoclassical) policy model that it uses to guide monetary policy - which is demonstrably misspecified insofar as it overlooks the long-run relationship between output and inflation characteristic of the Post-Keynesian structure of the economy - has been validated by the success of its policy intervention. As we will make clear in the next section, this second result is far from trivial and has broader implications for the conduct of stabilization policy.

\section{Further discussion: success in the small as a source of failure in the large?}

The analysis in section 2 tells a "good news, bad news" story for monetary authorities and for society as a whole. The good news is obvious: stabilization policy prosecuted using the Taylor rule can work even if it is based on an incorrect understanding of the economy. The policy model may be wrong, but the policy itself does more good than harm, stabilizing the economy in accordance with the central bank's chosen policy targets. In some sense, therefore, the analytical results obtained in the preceding section

can be interpreted as an alternative variant of the "good luck" interpretation of what caused the Great Moderation. In this case, however, what the monetary authorities were 
lucky enough to experience is quite different in nature and operation from the favourable exogenous shocks emphasized by Stock and Watson (2003).

The bad news is less obvious, but results from the potential for the good news to give rise to "policy model complacency” (Setterfield, forthcoming). If central bank policy succeeds even as the central bank's understanding of the economy is deficient, the dangerous possibility arises that policy success is misinterpreted as successful understanding of the workings of the economy, even when it is no such thing. This, in turn, creates vulnerability to surprises - specifically, events with systematic origins in the workings of the economy itself that are not anticipated by the monetary authority because they do not feature in its misspecified macroeconomic policy model. The greater the central bank's self-belief in its flawed understanding of the economy, the greater this vulnerability is likely to be. In fact, the flagrant failure of the micro-founded dynamic stochastic general equilibrium (DGSE) models of mainstream macroeconomics to even consider the possible emergence of the recent financial crisis is a demonstration of how destabilizing such vulnerability may be. As persuasively argued in Lavoie (2016), misguided economic policies relying on an unrealistic macroeconomic theory that denied the possibility of a crisis are at the root of the recent macroeconomic and financial malaise (see also Lavoie and Seccareccia, 2012).

This suggests that if the Great Moderation was, indeed, a “Great Deception”, then it was, as much as anything, the product of an act of self-deception on the part of central bankers that gave rise to unwarranted "master of the universe" delusions of grandeur (Greenspan as Maestro?). More significantly, the self-deception may have left policy makers dangerously ill-prepared for the sudden assertion of features of the "true model" that they never understood in the first place. After all, if the success of their policy indicated a complete and proper understanding of the workings of the economy, how 
could such surprises ever arise? So as much as it may have been an innocent fraud, the guilelessness of policy makers caught up in the Great Deception cannot excuse the resultant policy model complacency, because of the latter's potentially devastating costliness to society. Again, witness the Great Recession and its aftermath.

The solution to this problem is straightforward: policy makers should entertain substantially more eclectic views about how the economy might function. This amounts to a form of humility (and, in light of the results of the preceding section, a satisficing humility, say) that recognizes the fact that the efficacy of monetary policy over protracted periods of time does not, in and of itself, necessarily substantiate the notion that the monetary authority correctly understands the "true model” of the economy. In principle such (satisficing) humility is easy to practice, since there is no shortage of heterodox macroeconomic models that differ fundamentally from the still-dominant New Consensus, several of them associated with the work of Lavoie and Seccareccia. Moreover, these alternative models are provided freely by the academy, thus providing a zero-cost "safety net” capable of safeguarding society against the perils of policy-model complacency and self-deception in policy making.

\section{Conclusions}

Our analytical results show that in general, the endogenous adjustment of inflation expectations in accordance with satisficing evolutionary dynamics relaxes the constraint imposed on policy makers by the Tinbergen (1952) principle, allowing policy makers to pursue two explicit targets (output and inflation) using only one explicit instrument (monetary policy). However, the violation of the Tinbergen principle is only apparent, as the degree of heterogeneity in inflation foresight strategies across private agents becomes another adjusting variable that contributes (together with the actions of the central bank) 
to macro stabilization. In other words, our analysis brings to light a novel channel of monetary policy transmission working through the evolutionarily time-varying frequency distribution of inflation forecasting strategies within the private sector - what might be called an "inflation predictor heterogeneity" channel. Interestingly, the operation of this inflation predictor heterogeneity channel suggests that the presence of endogenously time-varying heterogeneity in the strategies used by private agents to form inflation expectations may actually facilitate rather than hinder monetary policy that claims to be based on the management of expectations.

Ultimately, our analytical results show that uncertainty in decision making resulting in evolutionarily time-varying heterogeneity in inflation expectations formation based on satisficing criteria does not necessarily thwart successful macroeconomic policy intervention by monetary authorities who, contrary to their own self-image, are also boundedly rational and implicitly engaged in satisficing behaviour (based on the achievement of fuzzy target values of variables of interest). As we have seen, the chief danger arising from all this is policy model complacency - a false sense of surety that arises from policy makers confusing policy success with a full and complete understanding of the "true model” of the economy. A ready solution to this problem exists and has been proposed - a solution to which the work of Marc Lavoie and Mario Seccareccia makes a substantial and invaluable contribution. 


\section{References}

Assa, J (2017) The Financialization of GDP: Implications for Economic Theory and Policy, London: Routledge.

Bernanke, B. (2004) “The Great Moderation,” Speech at the Meetings of the Eastern Economic Association, Washington, D.C., February 20.

(http://www.federalreserve.gov/boarddocs/ speeches/2004/20040220/default.htm)

Blanchard, O.J. and J. Simon (2001) "The long and large decline in U.S. output volatility,” Brooking Papers on Economic Activity, 1, 187-207.

Clarida, R., J. Gali, and M. Gertler (2000) "Monetary policy rules and macroeconomic stability: evidence and some theory,” Quarterly Journal of Economics, 105, 147-180.

Crowley, P. and A. Hughes Hallett (2014) "Volatility transfers between cycles: a theory of why the 'Great Moderation' was more mirage than moderation,” Bank of Finland Discussion Papers 23-2014.

Davis, S.J. and J.A. Kahn (2008) "Interpreting the Great Moderation: changes in the volatility of economic activity at the macro and micro levels," Journal of Economic Perspectives, 2, 155-180.

Dynan, K.E., D.W. Elmendorf, and D.E. Sichel (2006) "Can financial innovation help explain the reduced volatility of economic activity?” Journal of Monetary Economics, 53, 123-50.

Galí, J. and L. Gambetti (2009) "On the sources of the Great Moderation,” American Economic Journal: Macroeconomics, 1, 26-57.

Hommes, C. H. (2013) Behavioral Rationality and Heterogeneous Expectations in Complex Economic Systems, Cambridge, MA: Cambridge University Press.

Kahn, J.A., M. McConnell, and G. Perez-Quiros (2002) "On the causes of the increased stability of the U.S. economy," Federal Reserve Bank of New York Economic Policy Review, 8, 183-202.

Keating, J.W. and V.J. Valcarcel (2017) "What's so great about the Great Moderation?” Journal of Macroeconomics, 51, 115-42.

Lavoie, M. and M. Seccareccia (2004) Central Banking in the Modern World, Cheltenham: Edward Elgar.

Lavoie, M. and M. Seccareccia (2012) "Monetary policy in a period of financial chaos: the political economy of the Bank of Canada in extraordinary times", in L.P. Rochon and S.Y. Olawoye (eds.) Monetary Policy and Central Banking: New Directions in PostKeynesian Thought, Cheltenham: Edward Elgar, 166-189.

Lavoie, M. (1995) "The Kaleckian model of growth and distribution and its NeoRicardian and Neo-Marxian critiques,” Cambridge Journal of Economics, 19, 789-818. 
Lavoie, M. (1996) "Traverse, hysteresis and normal rates of capacity utilization in Kaleckian models of growth and distribution," Review of Radical Political Economics, 28, 113-147.

Lavoie, M. (2016) "Rethinking macroeconomic theory before the next crisis," Institute for New Economic Thinking, September 23.

(https://www.ineteconomics.org/perspectives/blog/rethinking-macro-theory)

Lima, G.T. and M. Setterfield (2008) "Inflation targeting and macroeconomic stability in a Post Keynesian economy,” Journal of Post Keynesian Economics, 30, 435-461.

Lima, G.T. and M. Setterfield (2014) "The cost channel of monetary transmission and stabilization policy in a Post Keynesian macrodynamic model,” Review of Political Economy, 26, 258-281.

Lima, G.T., M. Setterfield, and J.J. Silveira (2014) "Inflation targeting and macroeconomic stability with heterogeneous inflation expectations," Journal of Post Keynesian Economics, 37, 255-79.

McConnell, M. and G. Perez-Quiros (2000) "Output fluctuations in the United States: what has changed since the early 1980s?” American Economic Review, 90, 1464-76.

Setterfield, M. (2007) "The rise, decline and rise of incomes policies in the US during the post-war era: An institutional-analytical explanation of inflation and the functional distribution of income,” Journal of Institutional Economics, 3, 127-146.

Setterfield, M. (forthcoming) "Can monetary policy survive policy model misspecification? Model uncertainty and the perils of 'policy model complacency,"” Metroeconomica.

Simon H. A. (1955) “A behavioral model of rational choice," Quarterly Journal of Economics, 69, 99-118.

Simon H. A. (1956) "Rational choice and the structure of the environment," Psychological Review, 63, 129-138.

Stock, J.H. and M.W. Watson (2003) “Has the business cycle changed and why?” In M. Gertler and K. Rogoff (eds) NBER Macroeconomics Annual, Cambridge, MA: MIT Press, 159-218.

Tinbergen, J. (1952) On the Theory of Economic Policy, 2nd edition, Amsterdam: NorthHolland. 